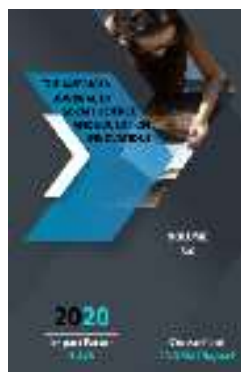

\title{
Classification Of Genres In Multimedia Journalism
}

\author{
Madinabonu Nuriddinova \\ Teacher, Journalism And Mass Communication University Of Uzbekistan
}

Journal Website:

http://usajournalshub.c

om/index,php/tajssei

Copyright: Original

content from this work

may be used under the

terms of the creative

commons attributes

4.0 licence.

\section{ABSTRACT}

The article focuses on multimedia issues that are gaining popularity in journalism. It also includes analysis of increasingly popular multimedia articles online, classification of multimedia genres, and transformation issues. Online format of data journalism, journalistic skills, classification online data materials are also covered in it. The virtual network genres are covered with a basis of extensive examples.

\section{KEYWORDS}

Innovation, broad-spectrum, synergetic phenomenon, informational genres, media information, perfect content, personal websites, blogging, social network, article, pragmatic solution, active network projects.

\section{INTRODUCTION}

The integrated format of online media data transmission has made it possible to produce and disseminate information quickly. This led to the study of student opinion and the creation of innovations that combined the characteristics of the perfect genre. Now it is necessary to carry out integration, recreational (creative) activities, virtual reality, adaptation to the cyber space, improvement, using Internet programs specific to the online audience. The constantly evolving broad- spectrum network trend has a significant impact on the ways in which data is presented, along with the genres, as well as the factor of reader acceptance. According to him, the function, structure, peculiarities and essence of these media genres have changed. According to the synergetic phenomenon of journalism, as the content of information is constantly changing, the process and tasks of news transmission are constantly evolving, constantly mixing with related fields. 


\section{MAIN PART}

Which method of coverage depends on the choice of the author. Online publications use more informational genres, and the total size of the text does not exceed 1,500 elements. In it, the facts of reality are mainly reflected as the subject of the studied process. [5-35] Divided according to the object of purpose and the method of presentation, the created text always belongs to three main types informational, analytical, artistic and journalistic. In the information market, information is a commodity and the audience is capital. The goal of journalism to inform and engage the audience more and more has been the basis for the creation of various forms, formats and genres. It is known that this practice was first introduced by Joseph Pulitzer, who expanded his business by painting entertainment pages in yellow. He selected the information appropriate to each layer and presented it to the public (the term yellow press originated in this way). The content on the Internet also reflects the needs of the reader, the demand of the audience, and the integration of different media information leads to the creation of perfect content. In online journalism, genres can be divided into types according to their typological features, and a mixture of formats can be observed at the same time. Virtual genres are studied into sub-genre, hyper-genre and hybrid genre categories. Any article on the network can be divided into reports, essays, feuilletons, correspondence. But it is difficult to find pure internet genres that are unique to online journalism; Due to the mass, communicative nature of the Internet, they can be classified as follows:
1. Communicative genres. It is mainly found in mass communication and social networks. Examples include echat, news feed, forums, and social media dialogues. For example, the blog-post, comment-forum genres on the social network Facebook.

2. Entertaining genres. Genres belonging to this category are widely used to attract the attention of readers and expand the network audience, in which a mixture of genres can often be observed. Instagram's authorship genres such as "classic" and "neopost" can be cited.

3. Presentation genres include personal websites, blogging, social networking articles, and comment text. Examples of this are the video blogging genres and monocomment genres on you tube.

4. Information genres include a series of texts used to obtain information electronic library, encyclopedia, news agencies, news sites, search engines, archive data, social media messages.

Referral genres include website, advertising, announcements, online store page texts, articles, social videos, charity and forum information.

Summer is a reporting genre. It is to combine the main ideas of different articles and create a text within the problem without too many details. It has the ability to generalize several types of reality and reflect them in a single text.

The relevance of genres, the media is changing and improving as a result of modern requirements (meaning the desire of the reader), the historical and political situation and technological inventions. That is, 
depending on the mood of the social stratum, some ideas may be needed or ignored altogether.

One of the important factors in the creation of a genre is the creation of a visual model of the phenomenon under study. This type of model is called a description of the presentation topic, and the description focuses on the problem + solution [58-3]. That is, the genre can often be used as a synonym for "definition" and "observation". In turn, the definition is an important component in the interpretation of journalistic events. "The main factor shaping genres is the ability to give a rational, cognitive image and pragmatic solution in the text.

The adaptation of genres to the online format in the presentation of information on the Internet is divided into three stages:

1. The first trend of the Internet; in which only the data segment of foreign users are developed. The information genres of financial, economic and commercial sites are a common stage.

2. Trends in active network projects; The first permanent online publications and various international projects were launched. After the second phase, the Internet was adopted by the population as a means of mass communication, an information space. This online press has published articles on a variety of topics, which can be used as an open source of information.

3. The trend of online resources. At this stage, major news agencies, databases, Internet resources, libraries, social networks were established. Now the network is enriched every minute with the information not only of experts in the field, but also of the reader (viewer, user). Therefore, the type, function and format of network genres have also expanded [45-67].

The information in the online newspaper is published in electronic form, which can be enriched not only with text, but also with multimedia genres in the form of photos, videos, animated elements, interactive commentary, conversation, infographics, long reads and maps. The multi functionality of the network changes the fundamental structure of the typology of genres, creating a number of obstacles in its analysis. Furthermore, since the international network is a rapidly changing medium, it is not possible to give a definitive conclusion about its internal structure and genres. The press genres, which were the first representatives of communication, are also widely used in the activities of other media.

According to the nature of multimedia, the multimedia genres used on the Internet combine various factors of information presentation - audio, visual, kinetic. The essence of genres involves the delivery of a complex of image elements to the consumer in a comprehensible way (verbal, graphic, sound, photographic, text, video, animation). Online content has succeeded in enriching traditional textual information with a variety of information technology applications. Multimedia technologies are actually widely used in other types of media as well; These include radio interactive broadcasts, various live broadcasts on television, and the exchange of letters between the press and the reader. But in a network, the user can see, select, process, and directly transmit the sum of all of these aspects into a single method.

In addition, the network module is notable for its popularity, interactivity, richness of hypertext, variety of language images and 
software. It also has four key features that ensure its synchronous operation: key elements, synthetic forms, multimedia applications, and projects. In orderly multimedia stories, there are introduction and end points of the topic. Reality is linked in an organic sequence, all maps, charts, pictures, links to blogs, infographics are provided. A chaotic story can end without an end. The most commonly used multimedia genres in multimedia storytelling, hypertext creation by Internet journalists are longrid, infographics, storimeps, and timeline.

Today, practicing journalists strive to make the information available to the public as short as possible, enriching it with programs in the form of media text. Since 60 percent of the Internet is made up of mobile users, simplification and refinement of data is a key task [7-29]. It is a little difficult for the masses living in the midst of millions of information to digest all the news at once. Therefore, the destruction of longform texts, including in the media and on the Internet, is taking place. There is a great demand for information written in light, easy language, enriched with text, pictures, videos, graphics and sounds.

Unlike other media, the Internet operates in an area full of various "waste" of information. This represents a huge barrier to providing information to the reader. It can be said that the solution of the multimedia genre was born out of this situation. It must be enriched with elements in the order of "text + audio + video". The coverage, features, text content of multimedia genres in the network are divided into a complex of pictorial, synthetic, audio, video genres. [11-403]

A multimedia story or article, as a specific type of information in online journalism, consists of information units of different genres, combining the features of interactivity and elements of media convergence. This media product is a combination of information in the form of sound, sound, text, graphics and video, ie multimedia hypertext. In terms of the structure of multimedia hypertext can include: hyperlinked text, video, photos, slide shows, audio, infographics, cartoons, interactive forms (online voting, reviews, ratings). They can be classified into primary and secondary components. Initial components can include referenced text, photos, videos or audios from other sources. No material is provided without references. Basic information is provided through picture elements. The text can be added in the form of comments, clarity, title. It is presented by different editors in different forms depending on the nature of their activities. New technological digitalization opportunities in the global network applications, various multimedia genres - have expanded the ability of process media convergence to receive information.

The ratio of information received by each individual living in the civilization of the twentieth century is equal to the coefficient of information that human civilization has read and sought throughout the entire century. That is, the need for information in man has become a major factor. Emerging as a detonation discovery of the age of globalization, the Internet has radically changed the concept of information monopoly in practice. Now every reader can broadcast their data live without any censors. This process can be done through the network's mass communication service.

The relative cheapness of the use of network information projects and the lack of centralized 
censorship have negatively affected the development of specialized newspapers and magazines. Typically, multimedia information is defined as a mixture of text, image, audio, and video technologies of an existing virtual entity. That is, practically all available technical means are the main resource of data transmission, which is characterized by the disappearance of the distinction between mass and individual communication. Therefore, the transformation process of information genres is undoubtedly one of the most important of the practical processes of the media field. The most hybrid form of traditional information genres in the network, as well as the most popular are:

1. Reportage + copyright stories $=$ Twitter Reportage; The type of information genre, which does not exceed 140-160 elements in total, is widespread on social networks. It is mainly broadcast in the form of additional podcasts to the online broadcast video.

2. Online diary. Widely used on the network as a copyright creation (e.g. instagram). In it, the author writes his thoughts and comments on current issues and news of the day. Text, video, photo elements can be widely used. $75 \%$ of Instagram social network consists of diaries where video and photo information is transmitted online.

3. Online note genre. Announcing news, facts, and current events with visual elements that grab the reader's attention. It is often displayed from different angles in the form of notes on various websites and social networks, news feeds, homepages of online publications.
4. News monitoring. The results of the survey conducted among users are expressed in the form of infographics or text. Various graphic elements, text, photos and photo collages can be used.

5. Author's blog. Among the users of the network, running a personal website, filling it with information is considered to be the most popular genre type. The popularity of a page is determined by the number of members and written comments, and it has the following types:

Videoblog. It consists of various shows, commentaries, monologues, online broadcasts, videos filmed by the author.

- Photoblog. The main focus is on photography; the author uses his own collection of photographs.

- Text blogging. Mainly a text article, reportage, live communication type.

- Microblog. It can consist of a collection of various notes, aphorisms, messages, interesting interviews, infographic images or videos, audio conversations, and can belong to the work of several authors.

6. In the genre of videoconferencing or videomost, information is transmitted live by one or more authors live without various editing and processing. It has the opportunity to write interactive comments, express additional opinions. This practice has been widely used in traditional television news shows. The difference between online video conferencing is that the content of news and video messages on this topic is regularly 
updated, comments and observations are monitored.

7. In multimedia commentary, comment + audio, video element + graphics + synchronous monitoring is performed. A full-format image of a video dedicated to a topic. It consists of graphic elements that reveal a witness's commentary or topic idea. For example, you can follow examples of multimedia commentary on Irreccomendded.ru. It contains various forms of comments dedicated to a specific topic of the consumer.

The two strong currents to the listed transformational information genres are the product of the ideological creativity of professionals and users. The Internet, as a broad media platform, offers ample opportunities for professionals as well as the general public. Therefore, the types of genres in the network, the number of copyrighted projects, the weight of sites are also expanding. Invented as a new method of communication, the international network has become the main source of information today. The capabilities of the Internet have radically reformed the process of information processing and distribution, data storage. That is, information in the media has changed form and content as a result of transformation; this multimedia phenomenon has been incorporated into various linguistic elements of news information - visual, textual, graphic and audiovisual formats. As a result, we can create a completely new product with great features, production technology, unique ease of mastering.

According to a study by neurobiologists, the human mind cannot digest more than 120 bits of information per second. The fact that a person communicates with another person or reads information in any media is equivalent to a 60-bit work rate. Daily information reception and processing is equivalent to 30 gigabytes, a total of one hundred thousand words, sound, image aggregation. That is, each person consumes 300 exobytes of information over a lifetime. If you communicate with two people at the same time, you are using a bar of biological energy. This means that it is impossible to communicate with three people at the same time. Therefore, the world's leading media has attracted the attention of the public, enriching the information as much as possible at its disposal, applications of different formats, intelligent robot filters at the level of artificial intelligence, conversion of information into hypertext links, convergence of different media features, integration of multimedia genres.

The Internet has become a major communication hub in the world as a major phenomenon of communication. For example, more than 21,270 television stations in the United States, China, and Europe broadcast 85,000 hours a day. But the audience spends an average of 5 hours a day watching TV. According to a study in the electronic journal Mediascope in 2020, the classification of indicators of media consumption by audience was as follows: 4 hours spent on television, 3 hours on radio, 1 hour on print media and 15 hours on the Internet.

\section{CONCLUSION}

In short, the multimedia genre is not very new discovery phenomen. Even before the invention of the Internet functions, were invented. For example, video and audio sources that can be added to books. The 
Internet has enriched it and made it possible to polish it in various formats. The main condition of multimedia is, first of all, that the text consists of different elements, and all these elements can be viewed on any technological platform. The photo, text, video, audio, animation, and graphic elements presented in the format were already invented by humans. It is limited to providing only one side in a particular vehicle. For example, newspaper text, TV text, image and sound, radio and audio recordings. That is, there was a need for an electronic platform that would present it as a universal complex. Now these different information elements are transformed into patterns of one genre, and the enriched form of the whole text is delivered to the readers in a multimedia direction in an understandable and interesting language in the network. Due to the algorithmic microcosm of the diversity of information in multimedia genres, we recommend using the word visual storytelling instead of this term.

\section{REFERENCES}

1. Bell D. The End of Ideology. On the Exhaustion of Political Ideas in the Fifties. Cambridge (Ma.), 1960. P. 403.

2. D. Visual Storytelling in the Age of PostIndustrial Journalism. Grabowicz P., Hernandez R., Rue J. Taxonomy of digital story packages. 2013. P. 35. URL: http://multimedia.

3. McAdams, M. Flash Journalism: How to Create Multimedia News Packages. Burlington, Mass.: Focal Press/Elsevier, 2005. P. 520. https://flashjournalism.com

4. Marcel Danesi. Dictionary of Media and Communications. Library of Congress
Cataloging-in-Publication Data. Print. USA. 2009 y. 192 p.

5. Noab Iliinsky\& Jilie Steele. Designing data Visualizations. Published by O’Reilly Media, Inc., 1005 Gravenstein Highway North, Sebastopol, CA 95472. Printed in the United States of America 2011. P.110.

6. Steven Heller \& Rick Landers. Infographic designers' sketchbook. Hardcover, architechtual press,. Pub. 2014. P. 351.

7. STEENSEN STEEN (2009C) "Online Feature Journalism: A Clash of discourses", Journalism Practice 3, P. 29.

8. Turing, A. (1950). Com.puting machinery and intelligence. Mind, 59 (236), pp. 433-460. Reprinted in Hofstadter, D., and Dennett, D. C., eds., The Mind's I (New York:Basic Books, 1981), P. 67

9. Walt Whitman Rostow, Theorists of Economic Growth from David Hume to the Present, 1990. P. 712. https://www.google.com

10. Zakhro Abdurakhim qizi Umarova. (2020). DIGITAL MEDIA EDUCATIONAL ENVIRONMENT: MEDIA RESOURCES AND THEIR ROLE. Journal of Central Asian Social Studies, 1(01), 66-74. https://doi.org/10.37547/jcass/volumeo 1issueo1-a7 